\title{
The Present Situation of the Arabic Language and the Arab World Commitment to Arabization
}

\author{
Mustapha Benkharafa \\ Department of Languages, Institute of Diplomatic Studies, Riyadh, KSA
}

\begin{abstract}
Arabic has long occupied an exceptionally important position in Arab history either because it is the language of Revelation of the Koran, or because it is viewed as providing the cement of Arab nationalism. Furthermore, Arabization represents for the Arabs an urgent necessity because it can not only revive and revitalize the Arabic language but also lead the Arab nation to regain its linguistic independence and repudiate cultural subservience on Western societies. The purpose of this study is to bring into light the challenges that Arabic and Arabization are facing in the present century and to examine the problems which affect the power of Classical Arabic either directly or indirectly as well as to refute those misconceptions associated with the process of Arabization.
\end{abstract}

Index Terms-Arabic language, Arabization, diglossia, bilingualism, colloquial Arabic, sociolinguistics, education

\section{INTRODUCTION}

A careful and thoughtful scrutiny will show that in the present day Arabic faces many problems. The nature of these problems varies extensively in terms of their acuity. The main concern of this paper is to examine them closely. On top of these comes the linguistic problem usually referred to by the term «diglossia ». Therefore, the study of language contact witnessed a tremendous progress since the first publications of Haugan and Weireich in the early fifties. Although it was Ferguson who first considered and examined the phenomenon of diglossia at length. As it will be clear later this linguistic duality in Arabic stands as a serious problem for classical Arabic and as a result for the competition between Classical Arabic and Colloquial Arabic. On the other hand, another more serious problem threatening Classical Arabic is bilingualism, namely French-Arabic bilingualism. Because of the attitudes associated with it, the Arabic language seems to lose weight in favor of foreign languages, namely French in the Maghreb and English in the Mashreq. All in all, Classical Arabic (henceforth CA) finds itself in a plight in that it fluctuates between two extremes. On the one hand, there is a strong competition between CA and regional dialects. On the other, there is competition of foreign languages trying to displace it.

A number of claims concerning the potentials of CA, notably in the fields of science and technology were advanced. These claims, which were first originated from European proponents, hold the belief that CA was far away from being fruitful in scientific and technical domains. In plain words, the purpose of such allegations is to cast doubts among Arabic speakers about their language. Later on, these views were supported by some Arab proponents themselves. The purport of such a well-designed campaign was also to convey the idea that CA was the main factor behind the underdevelopment of the Arab world. As an alternative, they all encouraged the use of dialects as well as the adoption of the Latin script in the writing system of Arabic in stead of the Arabic one.

All these factors led to the creation of a reformist movement whose main purpose was to protect and safeguard the Arabic language. This movement of Arabization entailed an utter devotion to the Arabic language in different domains. Nevertheless, Arabization is such a debatable issue that it oscillates between two extremes according to whether it is perceived of as a tool leading to development or as an instrument deepening the state of underdevelopment in which the Arab world is entangled to an extremely high extent.

\section{TRibulation of the ARABic LANGUAGE}

\section{A. The Diglossic Situation in Arabic}

The sociolinguistic situation of the Arabic language is characterized by the existence side by side of two varieties of the same language (Zughoul 1985, Hammoud 1982, Elbiad 1985, among others). This linguistic duality goes back to earlier periods of the Arabic language history ${ }^{1}$. This linguistic situation in Arabic stands as an obstacle particularly as far as $\mathrm{CA}$ is concerned.

Throughout the Arabic speaking world, two varieties of Arabic are used. The use of one and not the other is context related. In formal situations the use of the «high» variety is required ; in this case, it is CA. The «low» variety, on the

\footnotetext{
${ }^{1}$ Benkadour, A. wrote an article which he published in Faculty Annals (1985, No. 2) in which he gave a considerable as well as convincing account on how the so-called literary Arabic, which can be equated to a certain extent with Classical Arabic, is derived from the surrounding Arabic dialects in Saudi Arabia in the earlier periods of the history of Arabic.
} 
other hand, is expected to be used in informal situations as a medium of interaction within a closely personal environment. Hammoud (1982) rightly points out that $\square$ Arabic diglossia implies two varieties of the same language existing and developing side by side, each enjoying a particular status and fulfilling different sociolinguistic functions $\square$. (p. 15$)^{2}$

The availibility of abundant works done in the Arabic sociolinguistics show that there are numerous labels associated with the varieties of Arabic. Most of the different labels of Arabic mean more or less the same thing. The diversity at the level of labels aims perhaps at reaching a certain high degree of precision in order to detect the slightest difference that may exist between apparently identical varieties. Some of these labels are totally misleading and even confusing whereas others are relevant and to the point. By way of example, some scholars prefer to coin labels such as pre-Islamic Arabic, early Islamic Arabic, Middle Arabic, Modern Arabic, and so on and so forth (Bentahila, 1983) ${ }^{3}$ [3]. Others divised libels like : Classical Arabic, Literary Arabic, Koranic Arabic, and so on (Elbiad 1985, Zughoul 1985, among others). Obviously, this diversity is quite ambiguous. In this respect it is worth noting that such diversity is extremely ambivalent in that the labels do not $\square$ refer to grammatically distinct varieties $\square$ (Bentahila, 1983). For the sake of easiness, only two labels are to be used throughout this study. These are : CA to refer to the $\square$ high $\square$ form and Colloquial Arabic (henceforth CoA) to refer to the $\square$ low $\square$ form. As mentioned earlier, each of these varieties is used in specific domains and situations according to the function each has to fulfil.

CA is the medium of $\square$ the divine expression $\square$ in that it is the language in which the holy book was revealed and thus it has served as the main vehicle of Islamic culture. Furthermore, it is the language in which literary tradition of the past had been recorded and preserved until the present day. It has hardly undergone any change throughout its history. Cachia (1972), as quoted by Zughoul (1985, p. 203, 204) put it this way: $\square$ Above all, the Classical is the key to the immense treasure-chests of the past... Its stability has seldom been paralleled in other languages and today any Arab with a secondary education can if he is interested and prepared to go to little trouble, gain access to entire record of the past 1300 years. $\square$. Furthermore, CA is the language of written communication as well as the formal spoken variety used in political speeches, religious sermons and in all other formal situations. CoA, on the other hand, is the first language of almost all the Arabic speaking communities because it is natively acquired. It is also the spoken form that is used in everyday interaction. This variety of the Arabic language is considered as the lingua franca at the national level of each country. In fact it is quite obvious that there are as many Arabic dialects as there are Arabic speaking countries. However, the diversity of dialects does not end at the level of individual countries ; for even within a single country, we find a great number of regional dialects. These regional dialects differ from one region to another according to the distribution of linguistic items due to natural or social boundaries (Hudson 1980, p. 39). It is quite noticeable that CoA violates most of the rules which govern CA. $\square$ CoA is simpler than FA « Fus ḥ a Arabic » in syntax and lexicon. The I $\varepsilon$ rāb inflections are deleted. The dual is rarely used, and plural formation simpler. CoA is simpler, more frequent, more familiar vocabulary. It is also more open to borrowing from other languages. $\square$ (Zughoul, 1985, p. 205). Because of these features, CoA is seen as a distortion of CA. This is in fact the reason why it is associated with a number of negative connotations ${ }^{4}$. Nevertheless, CoA seems to exceed the domains in which it is expected to be used. This is probably due to peoples' proficiency in CA which is not efficient enough for total apprehension. To take just one example, if we allude to formal education where CA is supposed to be used, we will find that $\square$ teachers, then, have to spend time explaining in (low) material that has been presented in lectures and textbooks $\square$ (Fassold, 1984, p. 36). This is only one instance and there are many others in which CoA invades the domains in which CA is expected to be used.

Because it is not spoken in any Arabic speaking country, competence in CA is restricted to people who have reached a certain level of education. This implies that CA is learned solely through formal education. Thus, illiteracy means total ignorance of CA. In contrast to this, everyone in the community uses CoA as a vehicle to his everyday and ordinary conversation. It is possible to say that there is a kind of general agreement among scholars as regards the stability of diglossia in a speech community. As an alternative solution for this linguistic situation, almost scholars concerned with Arabic sociolinguistics proposed that the gap between CA and CoA dialects should be narrowed in favor of CA and that people should be encouraged to use $\square$ the supperposed variety $\square$, i.e. CA. Because the linguistic duality in Arabic cannot be deterred or done away with, at least in the near future, a great literacy campaign should, therefore, be fostered and put through all over the Arab world. This seems the only tangible way to reduce the strikingly high percentage of illeteracy among Arabic speakers.

\footnotetext{
${ }^{2}$ In the case of Morocco, the sociolinguistic situation is looked at as being multidiglossic. Though, we try to limit ourselves to the fact that all the varieties of Arabic, in Morocco, are to be considered as one- for the sake of the present study. Nonetheless and to arouse the reader's awareness, it is important to clarify briefly this multiglossic situation in Morocco: Classical Arabic is used for liturgical purposes and Islamic studies. Standard Arabic is used for the media and instruction (only 20\% of Moroccans can read and write Standard Arabic perfectly (Ennaji, 1991), but only a minority can speak it with some ease and fluency). Educated Moroccan Arabic, which is the result of mixing different grammatical aspects of Moroccan Arabic and Standard Arabic, is typically used in formal spoken situations by educated Moroccans (about $40 \%$ can speak it).

${ }^{3}$ These labels, therefore, are like those associated with the English language such as: Early English, Middle English, Standard English, Modern English and so on and so forth.

${ }^{4}$ Zughoul $(1985$, p. 205, 206) cited a number of quotations illustrating these negative connotations associated with Colloquial Arabic. Some of these are:" a language associated with ignorance and vulgarity" (Abdelmalek, 1972, p. 132)." the tongue of drunkards and servants...archaic, confused, having no rules of grammar...a mixture...a distortion of FA" (Mubarak, 1970, p. 41, 42)," a protégé of ignorance and imperialism" (Nasif, 1957, p. 49)," unworthy of being called a language and unfit to fulfil the aims of intellectual life" (Hussein, 1944, p. 236)," spread and favored by illeterates" (Fahmi, 1966, p. 150).
} 
Pointing the complexity of the linguistic behavior in Arabic speaking communities, Zughoul (1985, p. 202) rightly argues that $\square$ the diglossic situation is indeed problematic for a linguistic community. It is considered to be a hindrance to education and economic development, as well as a national coherence. $\square$ In spite of all this, the $\square$ diglossic situation $\square$ in Arabic does not constitute a serious problem when compared, for example, with the problem of bilingualism which is embodied in the excessive use of languages. It is quite noticeable that the foreign languages are extremely entrenched in the Arab world. In fact, these intruding languages represent a real challenge for the Arabic language and marginalize its role among its users.

\section{B. The Effect of Bilinguilasim on Arabic}

It seems that in order to understand the effects of bilingualism on the Arabic language in general and on CA in particular $^{5}$, the emphasis should be led first on the historical background that introduced the phenomenon into the Arab world. According to Fassold (1984), there are four main factors which may bring about the state of multilingualism. These factors are: Migration, imperialism, federation and border area multilingualism. For one reason or another, bilingual and multilingual communities vary in terms of the mainstream through which a society reaches this state of language diversity. Having previously been colonized by the Western imperialism, the Arab world bequeathed the languages of the colonizers. Therefore, the mainstream through which the Arab countries reached the state of multilingualism can be accounted for by imperialism. However, when it comes to the Arabic-Berber bilingualism, notably in the Maghreb, which had to do with the arrival of Islam rather than with imperialism or any other means of exploitation or domination. As for the Berber-Arabic bilingualism, the issue is considered in terms of both its origin and development (Bentahila 1983, Elbiad 1985). As regards this phenomenon of language diversity, Grosjean (1982, p.7) claimed that $\square$ In all parts of the world there are countries with one official language but with numerous languages, especially in Africa and Asia as a result of colonization... These countries on becoming independent had the problem of choosing an official language, it therefore had to have a written form and a varied and extensive vocabulary, that could serve as a means of communication with neighbouring states and as a symbol of nationhood. $\square$

It is quite possible, therefore, to say that there is a general agreement among many scholars that colonization is one of the most factors that gives birth to bilingual as well as to multilingual communities. From a synchronic point of view, the way both French and Arabic were introduced into the Maghreb differs according to the goals associated with the introduction of each of them. The French language, for instance, thrived as a new form of linguistic imperialism. Its use was imposed on the Western Arab countries as a way to control government, business and the various intellectual walks of life. Needless to say that the aim of such a strategy is to deepen the backwardness of the Arabic language in this part of the Arab world. On the other hand, the Arabic language is strongly linked with Islam to the extent that we cannot talk about the Islamic religion and at the meantime ignore the Arabic language and vice versa.

Arabic is the vehicle of Islamic tradition and culture and this is the reason why it is impossible to dissociate it from the Islamic religion. At the period of the new religion, Islam made its way to the regions of the Maghreb where most of its inhabitants were Berber. These people welcomed it very much. This acceptance of Islam implied the acceptance of Arabic as a tool accompanying this new belief. Furthermore this new tool is the language in which the Kuran is revealed. Therefore, any community which adopts Islam ought to learn the Arabic language in order for individuals to be able to recite Kuranic verses in prayers and other rituals ${ }^{6}$.

According to Elbiad (1985, p. 21), the arrival of the Arabs in North Africa constituted a crucial metamorphosis in the history of Berbers. This change was all-embracing as it influenced all the walks of their life. It indeed embodied a turning point in their lives because when the Arabs came they brought along with them $\square$ a new religion, Islam; a new language, Arabic; a new culture Arabo-Moslem $\square$. Consequently, Berbers showed great enthusiasm toward the new religion and devoted themselves to it. We can therefore conclude that there was no clash between the two $\square$ languages $\square$.

On the contrary, there was a kind of complementarity. Bentahila (1983) hit upon another point whereby he accounted for the Berbers' positive attitudes towards the Arabic language. The reason, according to him, is that Berbers lacked a language which has a writing system and they found Arabic supplying them with such a system. However, this is a minor reason behind these favorable attitudes towards Arabic when compared, for instance, with religious factors. On the opposite the introduction of foreign languages into the Arab world, namely French and English, has created a complex as well as controversial issue which has puzzled sociolinguists all over the Arab world until the present day.

The presence of French in the Maghreb and English in the Mashreq is one of the legacies of colonization which lingered in the Arab world for more than two centuries. Throughout this era the colonial authorities, French and British, imposed the propagation of their strong belief in their superriority in all levels and, in conjunction with this, they diminished the value of whatever belonged to the Arabs. $\square$...Their mission civilisatrice was based upon glorifying the language and culture of metropolis to the detriment of Arabic language and culture which had been suffering serious

\footnotetext{
${ }^{5}$ Classical Arabic is given too much weight throughout this paper because it is the core around which the present study revolves, and also because it is the language of Arabization.

${ }^{6}$ Ferguson (1959) wrote an article entitled «Myths about Arabic» in which he dealt profusely with this issue. He chose to use the term' myth' because of the way the Arabic speakers talk about their language. According to him, this way is not objectively or empirically based; nevertheless, he said that this is not always the case.
} 
setbacks since the nineteenth century. Instead of assigning Arabic to modern functions, it was associated with tradition and religious sentiments. $\square$ (Hammoud, 1982, p. 211).

A glance at the present linguistic situation all over the Arab world will show the extreme extent to which the colonial rule had been successful in implementing his deleterious policies of imposing French and English languages and undermining the Arabic language. This carries the implication that, even the Arab countries had gained their political independence, the colonial languages are still dominant in many fields. This dominance is the result of favorable attitudes associated with precision and modernity to the detriment of Arabic which has been associated with the past, imprecision, backwardness, emotions and the list seems unexhaustive. In the case of French in the Maghreb, $\square$ the role, function and status of the French language must understandably be of paramount importance. Not only is French linguistic code bequeathed by Moroccans but its presence as a foreign legacy is manifested in various forms. It is associated with ideologies, modes of life, values, higher education and technical knowledge. It is the symbol of modern world, Western culture and civilization, novelty and equality. $\square$ (Elbiad, 1985, p. 60).

This bilingual situation has been an intricate and controversial issue. Language planners have been working hard to devise a better language policy in the Arab world in which emphasis goes to the Arabic language without the least ignorance of the importance of learning and teaching foreign languages as an access to the modern world. In this respect many proposals have been advanced. They all amount to restrict the excessive use of foreign languages as well as enhance the use of CA in education, especially in scientific and technical subjects, administration, social life and in other walks of life.

To solve this chaotic linguistic situation, there should be an intense increase in the use of Arabic which was marginalized over a considerable period of time. Furthermore, motivations encouraging people to use CA are to be enhanced by promoting better chances and opportunities of access to well estimated jobs based on proficiency in CA. The ideal solution seems to be the adoption of a $\square$ well- balanced bilingualism $\square$ in which complementarity rather than assimilation is what is overwhelming. But as the historical experience shows, this kind of bilingualism is hardly within reach for any given linguistic community. Bilingual speakers always do favor one language over the other ${ }^{7}$ In such conditions, the Arabic language should not be under the mercy of foreign languages. All in all, the Arabic language should be raised to the right level in which it enjoys both the privilege and prestige which would match it with any other $\square$ developed $\square$ language.

To reach this stage, $\square$ instrumental motivations $\square$ in learning and teaching foreign languages are to be encouraged. In other words, learning French or English is to be rather an $\square$ enriching experience, where the individual adds a second language to his repertoire without any loss to his first language or his feeling of identification with his own cultural community. $\square^{8}$. This type of bilingualism is known as $\square$ additive bilingualism $\square$. In contrast to this, the opposite could be true in the case of $\square$ subtractive bilingualism $\square$ in which the individual becomes totally alienated to the group of the second language being acquired. This is to be a rare case among Moroccan bilinguals, but the issue of bilingualism still remains as problematic as ever.

Together with this crusade, it was noticeable that there grew another no less dangerous campaign which the colonial rule encouraged enormously. One of the major tasks of this campaign resided in replacing CA by its colloquial dialects. They based their claims on the assumption that Arabic is a dead language. They also made an artificial analogy between Arabic and Latin. From this perspective, they equated the Romance Languages, being off-shoots of Latin, which is now extinct, with Arabic and colloquial dialects as $\square$ languages $\square$ which sprung from CA.

\section{Conspiracy against Arabic: External and Internal Challenges}

Recently, European as well as Arab proponents have advanced a well organized campaign against CA. All of them pointed it out as being the major hindrance to the development of the Arab world. The best solution they proposed was that CA should give way to Arabic colloquials. To do so and few decades before colonization made its way into the Arab world, a number of European countries were very much interested in CoA. This was well manifested in their allotting intensive programs to teach CoA in many European schools, namely in Italy, Russia, France, etc. In the same way, European people who lived in Arab countries in their turn gave a great deal of attention to Arabic dialects. Both (Elaāzab, 1974 and Zoghoul, 1985) wrote profusely on this very issue and showed how these European proponents did their best to uproot the Arabs from their national identity as well as from their most unifying force, CA.

One of the most known of these proponents is William Wilcox, an engineer British Orientalist. He wrote a series of articles and gave lectures in which he set out his crusade against CA. In 1893 published in Al- Azhar magazine, an article entitled Why Egyptians do not have the talent of invention? He linked this lack to the Arabs' insistence in using al fuṣ ḥ a. In 1925 he even translated the Bible into CoA. In an article entitled Syria and Egypt, North Africa and Malta, People Speak Punic, not Arabic.Wilcox maintained that CoA spoken in Egypt, the Levant, the Maghreb and Malta is one and the same language, originally Canaanite, Phoenician, or Punic, languages that preceded Islam. Hence it is

\footnotetext{
${ }^{7}$ There is a plethora of titles in the field of bilingualism, as the bibliography of this paper attests. Most of these studies dealt with the issue in specific societal context. For available introductory books in the issue of bilingualism, both Hugo Beatens Beardsmore (1986) and François Grosjean (1982) wrote a convincing account in which they considered the different types of bilingualism as well as accounted for them both from the synchronic and diachronic point of view.

${ }^{8}$ In his article entitled «Social Factors in Language Retention», R.C. Gardner made an elaborate distinction between ' additive bilingualism' and' subtractive bilingualism'. Both terms were seemingly coined by Lambert.
} 
unrelated to classical Arabic. According to him both the backwardness and lack of invention and creativity in the Arab world were direct consequences of the use of CA, which is considered a dead language. In order for the Arabs to acquire a well developed sense of creativity, he proposed that Arabs should distance and detach themselves from the use of CA. Hence to reach a high degree of development, CA should be done away with to pave the way for Arabic dialects to take over.

Wilkox was not the only one to propagate for this call but there was a number of others. For example, The British Sloan Wilmore (1901), director of the Civil Courts in Cairo during the British occupation, wrote a book Local Arabic in Egypt. He called for the use of CoA instead of CA in literary writings. Wilmore's campaign was more venomous than Wilkox's in that Wilmore called not only for the substitution of CoA for CA, but transcended this by his calling for the adoption of the Latin language as a literary language and Latin letters in the system of writing instead of the Arabic letters. Within the same path, Louis Massignon, French Orientalist, delivered in 1929 a lecture in Paris entitled The Arabic Language will not survive unless it is written in Latin script. Within this frame, this campaign against CA received a lot of encouragement from the colonial authorities. All this can be accounted for by the fact that such a call would deepen the problem of diglossia in Arabic. Accordingly, the unity among Arabic countries would seem impossible to attain.

All of the above calls for the use of CoA have opponents and supporters among the Arabs. Strangely enough, among the supporters of such a call was the prominent leader of the Liberal Constitutional Party, A. Fahmi a classicist. In 1943 he suggested to the Academy of the Arabic Language the idea of replacing Arabic script with Latin script. Of course, this idea was vehemently rejected, criticized not only in Egypt, but also all over the Arab world. In fact such Arab proponents called for $\square$ Egyptian nationalism $\square$ as opposed to $\square$ Arab nationalism $\square$. According to Zughoul (1985, P. 208, 209) $\square$ The movement called for Egyptianization of language, arts and literature which implied using Egyptian Colloquial or reforming FA (fuṣ h a Arabic) by what Ahmad Al-zayyat (1937) called $\square$ linguistic tolerance $\square$, that is, using loan words and CoA lexical items in writing. Mohammed Teymour and Salāma Musa (1956) attacked FA and called for raising the level of CoA to that of a national language. $\square$ It is worthwhile saying that such a call is futile at best because it is based on the fallacy that CoA dialects are the off-shoots of CA whereas the opposite is what seems to work. It is also futile because it is a call of a minority which was tainted with the Western way of life and consequently got puzzled with it.

Furthermore, the futility of this call resided in the fact that it was based on an artificial analogy between CA and Latin, that is, the Latin language is now extinct and the Romance languages were derived from it and which are now used in its stead. Another shortcoming of this call is that it is a $\square$ separatist movement $\square$. Instead of enhancing the unity among Arabic countries, they encouraged $\square$ regionalism $\square$ and $\square$ separatism $\square$. Furthermore, it is quite obvious that all Arab traditions and cultures have been recorded in CA. The use of dialects would set obstacles to apprehend all what is recorded in CA, the Kuran being no exception. The state of underdevelopment of the Arab world is not to blame on the nature of the Arabic language itself but rather on the people who use the language and the attitudes they had towards it. As a reaction to this campaign, a nationalist movement emerged. This reformist movement gave due consideration to whatever is Arabic. Thus, the nationalists together with the Arabisants opted for complete Arabization.

\section{ARABIZATION AND MisconCEPTIONS}

Almost all Arabic speaking countries have become aware of the importance as well as the role of Arabization movement; however, the process has been quite problematic. In this respect, the determinations which have been brought about so far as regards the implementation of complete Arabization seem insuffiscient. Hence these ambivalent efforts to give Arabization the due weight it deserves may well be accounted for by the fact that many people still link it with negative connotations. People holding such ideas are more often than not those who are influenced to a high extent by the Western culture and thereby hold whatever pertains to the West as the archetype and the ideal example to follow. Over fifty years after their independence, the Arab countries still find themselves in a situation not very different from that of the colonial era.

It seems quite obvious that the reason behind such poor results as regards the outcome of the Arabization process is, no doubt, the lack of real committment to this process. Most of the time Arabization is seen by many people as a plea for retraction and isolation from the rest of the world. In the same way, they regard it as being far away from bringing about a bright future for the Arab world. Concerning the deficiencies of Arabic language, the proponents emphasize this point to the extent that one could single out the Arabic language among all the languages of the world as the sole language to know these setbacks. Many scholars make allusion to this particular point claiming that almost all the languages of the world know this phenomenon of inadequacy, though it varies intensively and extensively from one language to another.

Hence this is a universal phenomenon even in those languages which are perceived as $\square$ well developed $\square$. However, in its broad sense, Arabization entails a linguistic reformist movement to help Arabic attain a well developed state under the modernization process. The historical experience shows that any language blooms through utilization and contact or it loses its weight through marginalization or lack of usage. Undoubtedly, such attitudes toward Arabic language stand as an obstacle for the process of Arabization because favoring any foreign language, be it French or English, over Arabic is deepening the Arab world dependency on the Western culture. 


\section{A tool deepening the present state of underdevelopment}

Another no less confusing and unfounded belief is that the process of Arabization will cut out the Arab world from the modern world and consequently the underdeveloped notion of the Arab world will linger for ever. Because the Western world is supposed to be the source of any development, notably in the domains of science and technology, the Arabic language cannot cope with the streams of terms coined every now and then. From this perspective, promoting Arabic in all the walks of life widens, in a way or another, the gap between the developed world and underdeveloped one. Hence, for the sake of saving time, these $\square$ Westernized $\square$ people in the Arab world opted for foreign languages, namely French and English, at the expense of Arabic. Alluding to Moroccan society, it is claimed that it has opted for neither bilingualism nor for Arabization.

Accordingly, it becomes an evidence the salient neglection of Arabization as the overwhelming language policy for the Arab world. In this respect, we recognize three categories of attitudes towards Arabization : The traditionalists who opt for total Arabization in order to saveguard the Arabic language, traditions and culture. The modernists show reluctant and disinclined attitudes to Arabize. For them French language is adequate enough to teach scientific and technical skills. The advocates of such attitudes towards Arabic do not at all put the process of Arabization a step forward ; if anything, they stand on its way. The nationalists perceive the process of Arabization as a political ideology in that it is not only a kind of expression of patriotism but also as a deliberation from colonization. It becomes quite clear that these negative attitudes associated with Arabic are stressed to the point of absurdity, but the serious problem which constitutes a major hindrance for Arabization resides in people's reluctancy to use Arabic language and not in the so-called problems posed by the Arabic language itself. ${ }^{9}$

\section{Potentials of ARABiC}

It goes without saying that a language is an adaptable sociological organism. That is to say, it undergoes processes of growth and development in the same way as does the society in which it is spoken. Defects and inadequacies surrounding Arabic do not rise from the nature of the language itself, but rather from the people who use the language and the attitudes they hold towards it. And since history reveals that Arabic was a language of universal civilization and that it displayed its ability to meet the scientific and cultural requirements of the past, we should prove today that it is $\square$ still able to create new concepts for all arts $\square$.

The judgements we sometimes hear that Arabic is a dead language or that it is not flexible enough to replace foreign languages as a medium for scientific and technical discourse are beliefs that are not based on real evidence, but rather on impressionistic, maybe hostile, attitudes. These judgements and many others are of no value simply because they go contrary to the objective scientific analysis. Arabic, unlike what its enemies maintain, has all the necessary predispositions to incorporate as many concepts and ideas as possible. Semantics and morphology are the major linguistic levels upon which Arabic, like other languages of course, relies to build new vocabulary.

\section{REAL DIMENSIONS OF ARABIZATION}

One of the most ultimate goals of Arabization is to make Arabic a strong language capable enough to express the upto-date inventions in the fields of science and technology. In order for Arabic to attain this level, a number of efforts have been made to modernize and elevate Arabic at various levels, namely its script, vocalic system, punctuation, lexicon, grammar and so on and so forth (the Arabic language seems to be blamed for being inefficient at all these levels). Hence, holding up Arabic entails its promotion as a medium of instruction across all disciplines. In order to deal with the specific problems of $\square$ modernization $\square$ of the Arabic language and coining terminology, several organizations have been founded all over the Arab world. Language academies in the Middle East are one instance. To avoid any potential inconsistency among these academies and under the urgent need for a central language agency, the foundation of the IERA (Institut d'études et de recherche sur l'arabisation) took place under the direction of Lakhdar Ghazal who proved to be a very skilled scholar in this field. From this universal perspective, Arabization is an all embracing operation which taints all the walks of life with that quality of Arabness. Hence, Arabization in the end is a return to the authentic Arab identity in which the Arabic language assumes the role of official and national language in all aspects of life.

\section{A. Getting Rid of the Linguistic and Cultural Dependency}

\footnotetext{
${ }^{9}$ Al-Hazmi, S. (2005), in a paper submitted to the colloquy on Languages in the Era of Globalization wrote that " The Second Arab Human Development Report (2003) prepared by the UNDP, states that the Arabic language today is facing harsh challenges and a real crisis in terms of: Theory, teaching, grammar, vocabulary, usage, documentation, creativity and criticism. The UNDP Report calls for strengthening the linguistic shields of Arabic and sharpening its practical attributes which emphasize its universal character and its ability to assimilate new informational and technological development. The Report also calls for, as a matter of necessity, the Arabization of university education and the improvement of the methodology of teaching Arabic and modernizing its curricula... The translation movement in the Arab world at large is chaotic. The UNDP Report mentions that only 4.4 translated books per million people were published in the first five years of the 1980s (less than one book per million per year), while the corresponding rate in Hungary was 519 books per one million people and 920 books in Spain...Translation and interpretation is a major activity... which is expected to offer more access to scientific information not currently available in languages like Arabic."
} 
Because of the foreign influence, the linguistic situation became very intricate and problematic as well. The most paramount example is the excessive use of foreign languages and the noticeable reliance on the Western culture. The process of Arabization is, therefore, a revolutionary linguistic movement which has been introduced to react against such a chaotic situation in which Arabic is almost totally neglected, and an urgent need to restore the Arabic identity. In order for them to achieve this stage, Arabic should be considered the sole official and national language. This, in a sense, entails Arabic to assume all the social functions. Furthermore, this linguistic movement purports to do away with alien languages, which are reminiscent of periods of oppression and exploitation during the colonial rule.

Hence Arabization is extremely very well evaluated and estimated for its importance and role in the formation of an independent national character. In this way, Arabization is viewed as a national aspiration for a world of equal educational and socio-economic opportunities. In spite of all of this, Arabization as an institutionalized process seems to have received little support, if any, from the parts of the political authorities. The whole atmosphere almost in the entire Arab world does not seem to be in favor of Arabization. The foreign languages are still predominant in all aspects of life. The Arab world aims, therefore, at considering Arabization to be mandatory for preserving the purity of Arabic and Arabness. To do so, Arab countries are required more than ever to follow the example of Asian countries policy, like Japan and Korea, in changing the whole situation in favor of Arabic in stead of foreign languages. In other words the transition, from the stage of consumption of knowledge to its production, remains a must.

\section{B. The Promotion of a Strong Development to the Arab World}

The historical experience has shown that the aims of colonization are to exploit and gain profits from the colonized rather than to serve them. Thus, it is quite obvious that no development of the Arab world is to be expected so long as dependency on the legacy of colonization is prevalent. Arabization in this sense is pregnant with audacious qualities for a bright future for the Arab world. First, Arabization is not a separatist movement. It aims, then, to establish a well unifying Arab world. This unity of the Arab speaking community is quite important. Once this unity is achieved, a kind of complementarity is to take place among the Arab countries. It seems quite obvious that the dominance of foreign languages is a call of the minorities who extract extravagant advantages from the present situation. For these elitist minorities, the stagnation of this muzzy linguistic situation is the utmost aim. From this perspective, the need for total Arabization is quite intense and as attested no subsequent development is possible while the linguistic situation is not given its due weight.

\section{CONCLUSION}

It has been made clear that these unrealistic judgements are out of place because they go against the basic principles of objective scientific analysis. A brief assessment of the language has indicated that Arabic, by virtue of its richness in the semantic and morphological techniques of forming new words for basic lexical concepts, could only with a certain amount of ingenuity cope with any needs for more vocabulary.

More importantly, methods of teaching Arabic and its curricula, which are not as efficient as might be desired, should be revised, improved and modernized. Besides, in order for the language to play its historical role as it did in medieval times, it must not only be revitalized and enriched, but also unified and standardized. Without coordination of efforts at reviving the language, it would not be surprising to find a multiplicity of terms provived by different Arabic language academies for one and the same newly reduced concept; a state of affairs which is likely to lead to confusion and bring Arabization at the same time to complete failure.

A number of advantages have been cited to show that Arabization is actually a very urgent need and that using Arabic in all walks of life will undoubtedly put an end to a wide variety of problems in almost all vital fields of knowledge. What is therefore needed are huge efforts so as to attain all these aspirations. An important task such as this, calls for years of hard work, patience, perseverance and constant financial support.

\section{REFERENCES}

[1] Al-Aazab, M.A. (1974). Min tārikh al-lugha al-arabiyya fĩ muwajahat al-tahaddiyyāt, in Alwasi Al-Islāmi, No 236 , Mai 1974.

[2] Alioua, B. (1986). Reflexions sur le processus d'arabisation, in Lamalif, No 180, 34-39, Septembre 1986.

[3] Abbassi, A. (1977). A Sociolinguistic Analysis of Multilingualism in Morocco. Unpublished Ph.D. dissertation. University of Texas at Austin.

[4] Al-Hazmi, S. (2005). English and Arabization: Friends or Foes? Colloquy on Languages in the Era of Globalization, 20-22 February, King Khaled University, Abha, K.S.A.

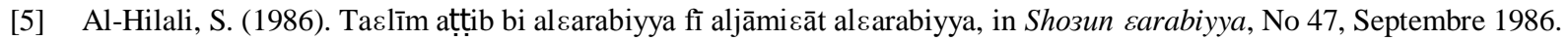

[6] Al-Kasimi, A. (1987). At-tąrib wa mushkilatuh fĩ al-wațan al-earabi, in Al-Manhal, No 452, Mars 1987.

[7] Al-Mandasi, M. (1987). Nahwa tąrib alıulūm fĩ aljāmiєāt al-maghribiyya, in Al-Mawqif, No 3, Septembre 1987.

[8] Badry, F. (1983). Acquisition of Lexical Derivational Rules in Moroccan Arabic: Implications for the development of Standard Arabic as a Second Language Through Literacy, Ph.D. dissertation, University of California, Berkely.

[9] Beardsmore, H.B. (1986). Bilingualism: Basic Principles. Second Edition. Multilingual Matters. Clevedon, Avon. England.

[10] Benkaddour, A. (1985). The Beginning of the Arabic Literary Language, in Annales de la Faculté des Lettres et des Sciences Humaines I, No 2, Hassan II University. 
[11] Benkharafa, M. (1995). Les Marques Modales dans un Corpus Spontané en Langue Seconde. Deux Sujets Hors Situation Scolaire: Une Etude Enonciative et Intonative, Université de La Sorbonne Nouvelle, Paris III.

[12] Benkharafa, M. (2001). Frankufūniyyat al-maghrib: Daєwa ilā at-tąrī̉b zam ilā al-izdiwājiyya, in The Diplomat, No 21, December, 2001.

[13] Benkharafa, M. (2010). Ibn khaldun wa-lmalaka llughawiyya, in The Diplomat, No 48, Janauary, 2010.

[14] Bentahila, A. (1983). Language Attitudes among Arabic-French Bilinguals in Morocco. Multilingual Matters. Clevedon, Avon. England.

[15] Benyekhlef, M. (1987). At-tąrīb wa al-muєāṣara, in Al-Wahda, No 33-34, Juin/Juillet 1987.

[16] Boufous, L. (1988). L'arabisation: Un dossier passionnant et désespérant, in L'Opinion, 15 Janvier 1988.

[17] Elbiad, M. (1985). A Sociolinguistic Study of the Arabization Process and its Conditioning Factors in Morocco, Ph.D. dissertation, New York.

[18] Elbiad, M. (1991). The Role of some Population Sectors in the Progress of Arabization in Morocco. International Journal of the Sociology of Language, volume 87, 27-44.

[19] Elbiad, M. (2005). Tuareg and Berber Languages. Encyclopedia of Linguistics, volume 2.

[20] Elbérini, M. (1975). Le problème linguistique et la lutte des classes, in Lamalif, No 76, 32-35, Novembre/ Décembre 1975.

[21] Ennaji, M. (1988). Language Planning in Morocco and Changes in Arabic. International Journal of the Sociology of Language, volume 74, 9-39.

[22] Ennaji, M. (1991). Multilingualism in the Maghreb. International Journal of the Sociology of Language, volume 87, 7-25.

[23] Ennaji, M. (2005). Multilingualism, Cultural Identity an Education Planning in Morocco. Springer.

[24] Essafi, F.A. (1985). Al-istihana bi al-Arabiyya wa al-3icraḍu canhā, in Arab Journal of Humanities, No 20, volume 5.

[25] Fasold, R. (1984). The Sociolinguistics of Society, Wiley-Blackwell, England.

[26] Ferguson, C.A. (1959). Myths about Arabic, in J. Fishman (ed.), Reading on the Sociology of Language, The Hague, Mouton.

[27] Gadner, R.C. (1979). Social Factors in Language Retention. Research Bulletin No 514. University of Western Ontario, London. Dept. of Psychology.

[28] Grandguillaume, G. (1983). Arabisation et Politique Linguistique au Maghreb. Coll. Islam d'hier et d'aujourd'hui. G.P. Maisonneuve et Larose. Paris.

[29] Grosjean, F. (1982). Life with two Languages: An introduction to Bilingualism. Cambridge University Press.

[30] Hammoud, N.S. (1982). Arabization in Morocco: A Case Study in Language Planning and Language Policy Atittudes, Ph.D. dissertation. University of Texas.

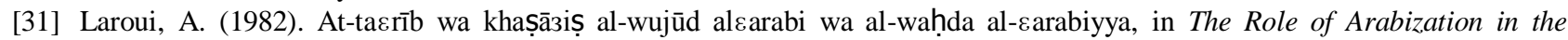
Advancing Arabic Existence and Unity, Mai 1982.

[32] Paulson, C.B. (1981). Bilingualism and Education, in Languages of the U.S.A. Ferguson C.A. (ed.), Cambridge University Press.

[33] Sonntag, S.K. and Pool, J. (1987). Linguistic Denial and Linguistic Self-Denial: American Ideologies of Language. in Language Problems and Language Planning, volume 11, No 1, 46-65.

[34] Youssi, A. (1995). The Moroccan Triglossia: Facts and Implications, in International journal of the sociology of language, No $112,29-43$.

[35] Zughoul, R.M. (1985). Diglossia in Arabic: Investigating Solutions, in Anthropological Linguistics, volume 22, No 5.

Mustapha Benkharafa was born in Salé, Morocco in 1963. He received his PH.D. degree in linguistics from La Sorbonne Nouvelle University, Paris III, France in 1995.

$\mathrm{He}$ is currently an assistant professor in the Institute of Diplomatic Studies, Riyadh, KSA. His research interests include theoretical linguistics, contrastive linguistics, applied linguistics, psycholinguistics, sociolinguistics and syntax.

Dr. Mustapha Benkharafa is a member in the permanent subcommittee of languages in the IDS. 